\title{
Effective Treatment of Small Uncomplicated Skin Abscesses with Fire Needle: A Case Series
}

\author{
Huan-Huan Zhang (D) \\ Chun-Min Zhang (D) \\ Qing-Qing Xu \\ Chun-Hong Zhang (DD
}

Department of Dermato-Venereology, The Second Hospital, Cheeloo College of Medicine, Shandong University, Jinan, People's Republic of China
Correspondence: Chun-Hong Zhang Department of Dermato-Venereology, The Second Hospital, Cheeloo College of Medicine, Shandong University, 247

Beiyuan Dajie Street, Jinan, 25000,

People's Republic of China

Fax +86-53I-88962544

Email aliu133@I63.com
Background: Uncomplicated skin abscesses are collections of pus within the skin structure and are usually caused by bacterial infections. Clinically, they are quite common and inevitably affect people of any age. The current management strategies comprise prompt initiation of antibiotics and incision and drainage. However, pain and the long healing process of skin lesions can cause distress to a lot of patients. Fire needling is a characteristic treatment in traditional Chinese medicine (TCM) and has proven effective in treating skin abscesses. Moreover, fire needle therapy has a more desirable cosmetic outcome in contrast to surgical debridement. The purpose of the study is to demonstrate the rapid, effective, minimally invasive, and better cosmetic outcomes of fire needles in the treatment of uncomplicated skin abscesses.

Methods: A total of 10 patients, aged between 1 and 45 years, with skin abscesses, were recruited. All patients who fulfilled the inclusion criteria with lesions less than $4 \mathrm{~cm}$ in diameter were topically treated with mupirocin ointment twice a day after fire needle therapy. If the lesion was still purulent after 2 days, it was treated again with fire needle therapy. The efficacy was assessed by a 4-grade scale at 2 days, 1 week, 2 weeks, 4 weeks and 12 weeks post-fire needling.

Results: Lesions with a diameter of less than $2 \mathrm{~cm}$ achieved significant remission (SR) or partial remission (PR), after 2 days post-treatment and reached complete remission (CR) or significant remission (SR) after 1 week following treatment. Meanwhile, lesions with a diameter of $2-4 \mathrm{~cm}$ achieved PR after 2 days and were assessed as CR or SR 1 week after post-fire needle therapy. None of the patients had a recurrence within 12 weeks after treatment.

Conclusion: Fire needle therapy is a promising treatment method for uncomplicated skin abscesses smaller than $4 \mathrm{~cm}$, which warrants further in-depth and more large-scale studies.

Keywords: fire needle, uncomplicated skin abscess, traditional Chinese medicine

\section{Introduction}

Skin infections are relatively common conditions in inpatient and outpatient settings. ${ }^{1}$ Furuncles and carbuncles form part of skin abscesses and are particularly frequent clinically. Many of these conditions share similar management strategies, including prompt initiation of antibiotics and incision and drainage when indicated. Wound care and follow-up care are critical parts of managing skin infections to ensure appropriate resolution and prevent further disease progression. ${ }^{2}$ However, incision and drainage inevitably lead to a larger wound, which is then allowed to heal by a secondary intention and hence involves a longer duration of wound healing. ${ }^{3}$ 
Fire needle therapy uses a stainless-steel needle with a diameter of $0.30 \mathrm{~mm}$. The wound is much smaller, and the pain is more bearable compared to current surgical treatment. Besides, local pus and blood discharge are also promoted through the small opening. In addition, these small wounds can promote the permeability of local drugs and improve the efficacy, avoiding the large surgical incisions, ${ }^{4-6}$ which may require secondary wound healing.

This paper reports on a series of 10 cases of uncomplicated skin abscess treated with fire needle therapy, which brought about a quick clearance of redness and swelling as well as excellent cosmetic outcomes. The study was approved by the Ethics Committee of the Second Hospital of Shandong University (Ethics No. KYLL-2019(KJ)P-0185).

\section{Methods}

\section{Inclusion Criteria}

We included patients diagnosed with uncomplicated skin abscesses with a diameter of less than $4 \mathrm{~cm}$ and who refused incision and drainage or had contraindications to incision and drainage.

Before treatment, we explained to each patient the operation process using fire needle therapy and the safety and precautions after the treatment. We then gave each patient or their legal guardian 30 minutes to decide and obtain verbal consent from all patients or their legal guardian, and sign informed consent in the treatment room before treatment.

\section{Treatment Protocol}

We obtained all the patients' or their guardians' consents for the publication. After disinfecting the skin lesion with $75 \%$ alcohol, the lesion was treated with fire needle therapy. We chose disposable sterile stainless-steel acupuncture needles $(0.30 \times 25 \mathrm{~mm}$, Wujiang Yunlong Medical Instrument Co Ltd). We chose the appropriate number of needles utilized during the treatment according to the patient's tolerance. The lower part of the needle was heated using a spirit lamp until the needle was red-hot. The heated needle was then used to puncture the skin abscess lesion (approximately the depth of the skin abscess sac wall) at a 90 degrees angle for about 0.5 $\mathrm{s}$ before swiftly removing it. The needle spacing on the lesion was kept at around $0.5 \mathrm{~cm}$ apart (Figure 1C). We asked the patients to keep the lesions away from water and skin care products for $24 \mathrm{~h}$.

After piercing the skin with the fire needle, the blood and/or pus were gently squeezed out and cleaned with cotton swabs. Finally, we applied a $0.5 \mathrm{~mm}$ thick mupirocin ointment on the lesion with a sterile cotton swab. After treatment, the patients were asked to apply a similarly thick layer of mupirocin ointment twice a day on the lesion.
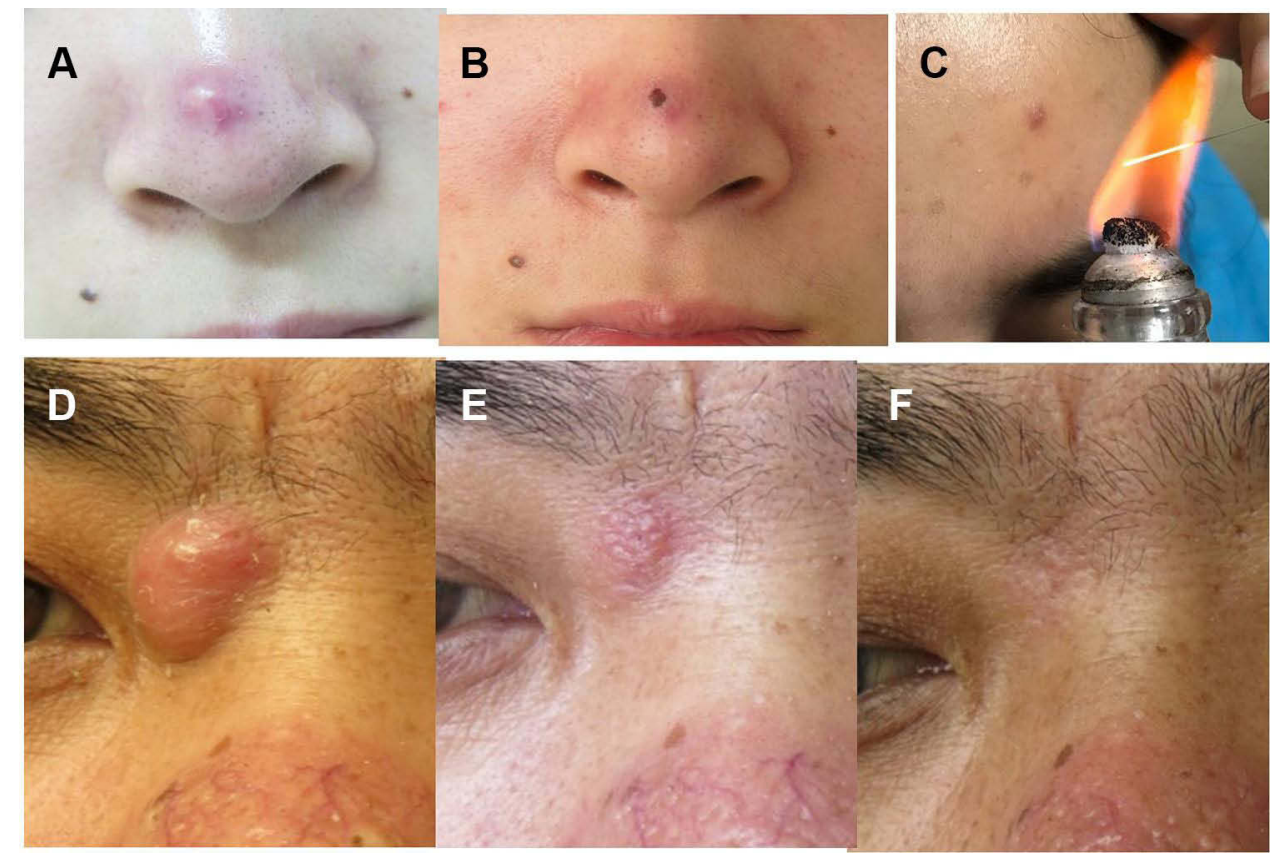

Figure I Patient I: A furuncle on the nasal tip. (A) Lesion before fire needle therapy. (B) Lesion 2 days after fire needle therapy. (C) Fire needle therapy. Patient 4: A skin abscess on the right medial canthus. (D) Lesion before fire needle therapy. (E) Lesion 10 days after fire needle therapy. (F) Lesion after one year of fire needle therapy; no recurrence within one year. 
2 days following the initial treatment, we assessed the patient's condition. If fire needling was effective and the disease did not progress, but there was still pus, the patient could be treated with fire needles again. If there was progress and/or fire needle therapy did not work, we further assessed the condition of these patients with a B-scan ultrasonography and gave them oral or intravenous antibiotics. Patients with suppuration were referred for surgery.

Apart from the pain attributed to needle insertion, we did not identify any other side effects.

Patients' baseline data were recorded during an outpatient visit. Efficacy was assessed using a 4-grade scale: 1) complete remission (CR): complete disappearance of lesions and symptoms; or $\geq 90 \%$ reduction of erythema, swelling and symptoms; 2) significant remission (SR): 60-90\% reduction of erythema and swelling, significant improvement of symptoms; 3) partial remission (PR): $30-60 \%$ reduction of erythema and swelling, some improvement of symptoms; 4) no remission (NR): $<30 \%$ reduction of erythema and swelling, little improvement of symptoms. Follow-ups were performed at 2 days, 1 week, 2 weeks, 4 weeks and 12 weeks after the first treatment of fire needle therapy. Follow-up was terminated when recurrence was observed.

\section{Results}

Our study included 10 patients, including 5 women and 5 men, aged 1 to 45 years old. The course of the disease ranged from 3 days to 30 days (Table 1). Patients 3, 4 and
7 did not receive any treatment before the initial visit. The effect of external antibiotic ointments on the other patients before their first visit was not satisfactory.

Patients 1 and 2 achieved PR 2 days after one fire needle therapy and achieved SR 1 week later due to their smaller skin lesion and early onset. Patients 4 and 8 received fire needle therapy twice because of more pus, achieving SR and CR at 1 and 2 weeks, respectively, after treatment. Except for patient 4, who achieved SR 1 week after treatment due to a longer medical history, other patients with abscesses measuring less than $4 \mathrm{~cm}$ in diameter all achieved CR 1 week after treatment (Tables 2 and 3). Representative images are shown in Figure 1A, B, D-F. All patients had no recurrence within the 12 weeks after treatment. There was no reported recurrence in patient 4 after a 1-year follow-up post-fire needling.

All treatments were well tolerated, with patients complaining of moderate pain at most that quickly subsided after a fire needle intervention.

\section{Discussion}

Abscesses are collections of pus within the dermis and deeper skin tissues. They are often caused by a progression of skin infections. ${ }^{2}$ Infections can progress rapidly, and early recognition and proper medical and surgical management are the cornerstones of successful therapy. ${ }^{7}$ Skin abscesses manifest as painful, tender, fluctuant, and erythematous nodules, frequently surmounted

Table I Baseline Data of the Study

\begin{tabular}{|c|c|c|c|c|c|c|}
\hline \multirow[t]{2}{*}{ No. } & \multirow{2}{*}{$\begin{array}{c}\text { Age at } \\
\text { Presentation } \\
\text { (Year) }\end{array}$} & \multirow[t]{2}{*}{ Sex } & \multirow{2}{*}{$\begin{array}{c}\text { Disease } \\
\text { Course (Day) }\end{array}$} & \multicolumn{2}{|c|}{ Baseline (Before Treatment) } & \multirow{2}{*}{$\begin{array}{l}\text { Fire Needle } \\
\text { Therapy (Times) }\end{array}$} \\
\hline & & & & Lesion Size & Symptoms & \\
\hline Pt I & 27 & $\mathrm{~F}$ & 3 & $<2 \mathrm{~cm}$ & Moderate pain and tenderness & 1 \\
\hline Pt 2 & 23 & $\mathrm{~F}$ & 5 & $<2 \mathrm{~cm}$ & Moderate pain and tenderness & 1 \\
\hline Pt 3 & 45 & $\mathrm{~F}$ & 7 & $<2 \mathrm{~cm}$ & Mild pain and tenderness & 1 \\
\hline Pt 4 & 36 & M & 14 & $<2 \mathrm{~cm}$ & Tenderness and no pain & 2 \\
\hline Pt 5 & 1.5 & M & 5 & $<2 \mathrm{~cm}$ & Moderate tenderness & 1 \\
\hline Pt 6 & I & M & 6 & $<2 \mathrm{~cm}$ & Moderate tenderness & I \\
\hline Pt 7 & 36 & $\mathrm{~F}$ & 7 & $2 \mathrm{~cm}-4 \mathrm{~cm}$ & Moderate pain and tenderness & I \\
\hline Pt 8 & 8 & $\mathrm{~F}$ & 7 & $2 \mathrm{~cm}-4 \mathrm{~cm}$ & Moderate pain and tenderness & 2 \\
\hline Pt 9 & 2 & $M$ & 8 & $2 \mathrm{~cm}-4 \mathrm{~cm}$ & Mild pain and tenderness & 1 \\
\hline Pt 10 & 16 & M & 30 & $<2 \mathrm{~cm}$ & $\begin{array}{l}\text { Mild pain, tenderness, and occasional pus } \\
\text { discharge }\end{array}$ & 1 \\
\hline
\end{tabular}


Table 2 Effectiveness of the Study

\begin{tabular}{|c|c|c|c|c|c|c|c|c|}
\hline \multirow[t]{3}{*}{ No. } & \multicolumn{8}{|c|}{ Efficacy and Follow-Up } \\
\hline & \multicolumn{2}{|c|}{2 Days After Treatment } & \multicolumn{2}{|c|}{ I Week After Treatment } & \multicolumn{2}{|c|}{$\begin{array}{l}2 \text { Weeks After } \\
\text { Treatment }\end{array}$} & \multicolumn{2}{|c|}{$\begin{array}{l}4 \text { Weeks After } \\
\text { Treatment }\end{array}$} \\
\hline & $\begin{array}{l}\text { Erythema } \\
\text { and } \\
\text { Swelling }\end{array}$ & Symptoms & $\begin{array}{l}\text { Erythema } \\
\text { and } \\
\text { Swelling }\end{array}$ & Symptoms & $\begin{array}{l}\text { Erythema } \\
\text { and } \\
\text { Swelling }\end{array}$ & Symptoms & $\begin{array}{l}\text { Erythema } \\
\text { and } \\
\text { Swelling }\end{array}$ & Symptoms \\
\hline Pt I & $\begin{array}{c}\text { Reduced by } \\
70 \%\end{array}$ & $\begin{array}{c}\text { No pain and tenderness, } \\
\text { no pus discharge }\end{array}$ & Cure & None & & & & \\
\hline Pt 2 & $\begin{array}{c}\text { Reduced by } \\
60 \%\end{array}$ & $\begin{array}{c}\text { No pain and tenderness, } \\
\text { no pus discharge }\end{array}$ & Cure & None & & & & \\
\hline Pt 3 & $\begin{array}{l}\text { Reduced by } \\
30 \%\end{array}$ & $\begin{array}{c}\text { No pain and occasional } \\
\text { pus discharge }\end{array}$ & $\begin{array}{c}\text { Reduced by } \\
90 \%\end{array}$ & $\begin{array}{l}\text { No pain and pus } \\
\text { discharge }\end{array}$ & Cure & None & & \\
\hline Pt 4 & $\begin{array}{c}\text { Reduced by } \\
30 \%\end{array}$ & $\begin{array}{l}\text { No pain, tenderness and } \\
\text { occasional pus discharge }\end{array}$ & $\begin{array}{l}\text { Reduced by } \\
60 \%\end{array}$ & $\begin{array}{l}\text { No pain and pus } \\
\text { discharge }\end{array}$ & $\begin{array}{c}\text { Reduced by } \\
90 \%\end{array}$ & $\begin{array}{c}\text { No pain and } \\
\text { pus } \\
\text { discharge }\end{array}$ & Cure & None \\
\hline Pt 5 & $\begin{array}{c}\text { Reduced by } \\
40 \%\end{array}$ & $\begin{array}{l}\text { Mild tenderness, } \\
\text { occasional pus discharge }\end{array}$ & $\begin{array}{c}\text { Reduced by } \\
90 \%\end{array}$ & $\begin{array}{c}\text { No tenderness } \\
\text { and pus } \\
\text { discharge }\end{array}$ & Cure & None & & \\
\hline Pt 6 & $\begin{array}{c}\text { Reduced by } \\
30 \%\end{array}$ & $\begin{array}{l}\text { Mild tenderness, no pus } \\
\text { discharge }\end{array}$ & $\begin{array}{l}\text { Reduced by } \\
90 \%\end{array}$ & $\begin{array}{c}\text { No tenderness } \\
\text { and pus } \\
\text { discharge }\end{array}$ & Cure & None & & \\
\hline Pt 7 & $\begin{array}{l}\text { Reduced by } \\
30 \%\end{array}$ & $\begin{array}{c}\text { No pain, mild } \\
\text { tenderness and } \\
\text { occasional pus discharge }\end{array}$ & $\begin{array}{l}\text { Reduced by } \\
90 \%\end{array}$ & $\begin{array}{l}\text { No pain, } \\
\text { tenderness and } \\
\text { pus discharge }\end{array}$ & Cure & None & & \\
\hline Pt 8 & $\begin{array}{c}\text { Reduced by } \\
40 \%\end{array}$ & $\begin{array}{c}\text { No pain, mild } \\
\text { tenderness and } \\
\text { occasional pus discharge }\end{array}$ & $\begin{array}{c}\text { Reduced by } \\
70 \%\end{array}$ & $\begin{array}{l}\text { No pain, } \\
\text { tenderness and } \\
\text { pus discharge }\end{array}$ & $\begin{array}{c}\text { Reduced by } \\
90 \%\end{array}$ & None & Cure & None \\
\hline Pt 9 & $\begin{array}{c}\text { Reduced by } \\
40 \%\end{array}$ & $\begin{array}{l}\text { No pain, tenderness and } \\
\text { occasional pus discharge }\end{array}$ & $\begin{array}{l}\text { Reduced by } \\
90 \%\end{array}$ & $\begin{array}{l}\text { No pain, } \\
\text { tenderness and } \\
\text { pus discharge }\end{array}$ & Cure & None & & \\
\hline Pt 10 & $\begin{array}{c}\text { Reduced by } \\
30 \%\end{array}$ & $\begin{array}{c}\text { No pain, tenderness and } \\
\text { pus discharge }\end{array}$ & $\begin{array}{c}\text { Reduced by } \\
90 \%\end{array}$ & $\begin{array}{l}\text { No pain, } \\
\text { tenderness and } \\
\text { pus discharge }\end{array}$ & Cure & None & & \\
\hline
\end{tabular}

by a pustule and surrounded by a rim of erythematous swelling. ${ }^{1,2}$ Spontaneous drainage of purulent material may occur, and regional adenopathy may be observed. ${ }^{2}$ Based on our literature review, incision and drainage are the primary and definitive treatments of abscesses. ${ }^{2,8-11}$ Small abscesses are often self-limiting and need little to no treatment. ${ }^{12}$ Antibiotics are not recommended as an adjuvant to incision and drainage, except in cases of systemic manifestations or impaired host defenses. ${ }^{13}$ Therefore, the only way to treat an abscess is to open the pocket and drain the pus. ${ }^{14}$ Opinions on the surgical treatment are divided between saucerization, and simple incision and drainage, especially for large abscesses. ${ }^{15}$ As an alternative to incision and drainage, fire needle therapy works by puncturing the abscess to drain the pus through a tiny vulnus.

Fire needle therapy was first recorded in The Yellow Emperor's Canon of Medicine, one of the earliest medical books in China. In the 1980s-1990s, the theoretical system of fire needle therapy developed rapidly and was more systematic. ${ }^{16}$ It is one of the three main types of acupuncture in traditional Chinese medicine and has the dual 
Table 3 Prognosis of Patients in This Study

\begin{tabular}{|l|c|c|c|c|c|}
\hline \multirow{2}{*}{ No. } & \multicolumn{5}{|c|}{ Prognosis } \\
\cline { 2 - 6 } & $\begin{array}{c}\text { 2-Day } \\
\text { Follow- } \\
\text { Up }\end{array}$ & $\begin{array}{c}\text { I-Week } \\
\text { Follow- } \\
\text { Up }\end{array}$ & $\begin{array}{c}\text { 2-Week } \\
\text { Follow- } \\
\text { Up }\end{array}$ & $\begin{array}{c}\text { 4-Week } \\
\text { Follow- } \\
\text { Up }\end{array}$ & $\begin{array}{c}\text { I 2-Week } \\
\text { Follow- } \\
\text { Up }\end{array}$ \\
\hline Pt I & SR & CR & NR & NR & NR \\
Pt 2 & SR & CR & NR & NR & NR \\
Pt 3 & PR & CR & NR & NR & NR \\
Pt 4 & PR & SR & CR & NR & NR \\
Pt 5 & PR & CR & NR & NR & NR \\
Pt 6 & PR & CR & NR & NR & NR \\
Pt 7 & PR & CR & NR & NR & NR \\
Pt 8 & PR & SR & CR & NR & NR \\
Pt 9 & PR & CR & NR & NR & NR \\
Pt 10 & PR & CR & NR & NR & NR \\
\hline
\end{tabular}

Abbreviations: $P R$, partial remission; $S R$, significant remission; $C R$, complete remission; NR, no recurrence.

functions of heat power and acupuncture. ${ }^{17}$ In recent years, fire needle therapy has reportedly been used to treat bacterial infectious dermatosis. ${ }^{16,18,19}$ The needles used in those studies were larger than $0.6 \mathrm{~mm}$ in diameter and can easily cause pain and leave scars, limiting the application of fire needle therapy. Therefore, we chose stainless-steel acupuncture needles with a diameter of $0.30 \mathrm{~mm}$ to improve the patient's tolerance of pain, and in all cases, we only used one needle during treatment. Based on our literature review, fire needle therapy can quickly eliminate or improve local tissue edema and adhesion to repair the damaged tissue. An animal study revealed that fire needle therapy had good therapeutic results on chronic soft tissue injury. ${ }^{20}$

The 10 cases reported above were challenging as their lesions were located in important areas that needed high aesthetic or had functional requirements. Fire needle therapy not only possesses an excellent clinical effect but can also achieve a favorable cosmetic outcome. All patients in this study could live and work as usual after the fire needle therapy. This alternative therapy promotes the discharge of pus through minor wounds and can also facilitate the absorption of topical drugs. More importantly, it is less painful than surgical incision and drainage and leaves less obvious scars.

In all cases, patients reported a notable and rapid decrease in pain after the fire needle therapy. And the wounds healed completely in about several days to three weeks, with no significant cosmetic concerns.

Aprahamian et $\mathrm{al}^{21}$ described that micro-incisions and loop drainage is a safe and effective treatment modality for subcutaneous abscesses in children. Another study described how most abscesses could be drained with a single small incision, which was safe, efficacious and led to better cosmetic results. ${ }^{11}$ Ngui et al ${ }^{3}$ reported three facial carbuncle cases with minimal necrotic tissue debridement, pus drainage and copious irrigation with gentamicin solution. The wounds healed in about two to four weeks, with no major cosmetic concerns. We believe that their method bears similarities to fire needle therapy, which also shows effectiveness in the early stage of abscess without suppuration. Patients 1 and 2 were treated in the early stage, and the time to reach SR and CR was significantly shortened. We only used the fire needle method alone for uncomplicated skin abscesses of less than $4 \mathrm{~cm}$ in diameter. Because fire needle therapy has the characteristics of minimal trauma, good efficacy, technically less demanding, requires less medical equipments, low cost, and results in no significant scarring, we advocate the use of fire needle therapy in the treatment of uncomplicated skin abscesses. It is especially good for abscesses in areas that require high cosmetic or functional requirements, such as the face, neck and breast. Furthermore, it might be suitable for patients who cannot tolerate or refuse surgical debridements, such as children and the elderly. Fire needle therapy can quickly relieve swelling and pain, control the development of skin abscesses, thereby reducing the use of intravenous or oral antibiotics and incidence of bacterial resistance. In conclusion, fire needle therapy is a simple and safe treatment, which may be an effective alternative strategy for dealing with uncomplicated skin abscesses.

Abscesses are a common form of skin and soft-tissue infections and are increasing in incidence. It is not difficult to diagnose by careful history and clinical examination. Although the standard approach of incision and drainage remains a mainstay of abscess management, the use of fire needle therapy may be considered in appropriate cases and may even provide a better alternative.

\section{Conclusion}

The present study was designed to determine the effect of fire needles on uncomplicated skin abscesses. The findings indicate that fire needle therapy showed a quick reduction in pain, promoted rapid recovery of the infection, provided significant benefits in terms of cosmetic outcome, reduced the systemic use of antibiotics and lowered patients' medical costs. In general, fire needle therapy is a likely 
alternative, conservative and promising treatment method for small uncomplicated skin abscesses.

\section{Acknowledgments}

All the authors thank the operators of all cases, Ying-Cai, Changyu-Han, Mengdi-Sun, Lu-Cui. We also thank all patients and their guardians for their consent to the publication.

\section{Funding}

This work was supported by the National Natural Science Foundation of China (81973856), the Natural Science Foundation of Shandong Province (ZR2017MH126).

\section{Disclosure}

All authors declare that there are no conflicts of interest.

\section{References}

1. Stulberg DL, Penrod MA, Blatny RA. Common bacterial skin infections. Am Fam Physician. 2002;66:119-124. doi:10.1080/00325 481.1993.11701692.

2. Ibrahim F, Khan T, Pujalte GGA. Bacterial skin infections. Prim Care. 2015;42:485-499. doi:10.1016/j.pop.2015.08.001.

3. Ngui LX, Wong LS, Shashi G, Abu Bakar MN. Facial carbuncle a new method of conservative surgical management plus irrigation with antibiotic-containing solution. J Laryngol Otol. 2017;131: 830-833. doi:10.1017/S0022215117000834.

4. Zhang Zhao-hui M, Xuya JL, Qiang X. The application of annular drainage with electric pyropuncture needle for treatment of patients with diabetic foot. Chin J TCM W M Crit Care. 2012;19:220-222.

5. Guo H, Liu G. Clinical observation of electric fire needle drainage combined with local closure in the treatment of head abscess perforating perifolliculitis. Tianjin J Tradit Chin Med. 2016;33:541-544.

6. Shen H, Gu J, Feng Q, et al. Clinical observation on abscess of breast carbuncle in purulent stage treated by burning hole with fire needle and adding medicine line drainage. JETCM. 2014;23:2127-2128.

7. Brook I. Microbiology and management of soft tissue and muscle infections. Int J Surg. 2008;6(4):328-338. doi:10.1016/j.ijsu.2007. 07.001
8. Talan DA. Adjunctive antibiotics for drained skin abscesses improve clinical cure rate. Evid Based Med. 2017;22:214. doi:10.1136/ebmed2017-110815

9. Vermandere M, Aertgeerts B, Agoritsas T, et al. Antibiotics after incision and drainage for uncomplicated skin abscesses: a clinical practice guideline. BMJ. 2018;360:1-8. doi:10.1136/bmj.k243

10. Aung KK. Guideline: TMP-SMX is recommended after uncomplicated skin abscess incision and drainage. Ann Intern Med. 2018;168: JC50. doi:10.7326/ACPJC-2018-168-10-050

11. Singer AJ, Talan DA. Management of Skin abscesses in the era of methicillin-resistant Staphylococcus aureus. $N$ Engl $J$ Med. 2014;370:1039-1047. doi:10.1056/nejmra1212788

12. Galli L, Venturini E, Bassi A, et al. Common community-acquired bacterial skin and soft-tissue infections in children: an intersociety consensus on impetigo, abscess, and cellulitis treatment. Clin Ther. 2019;41:532-551.e17. doi:10.1016/j.clinthera.2019.01.010

13. Stevens DL, Bisno AL, Chambers HF, et al. Executive summary: practice guidelines for the diagnosis and management of skin and soft tissue infections: 2014 update by the infectious diseases society of America. Clin Infect Dis. 2014;59(2):147-159. doi:10.1093/cid/ ciu296

14. Baiu I, Melendez E. Skin abscess. JAMA. 2018;319(13):1405. doi:10.1001/jama.2018.1355

15. Guan Hee T, Jan Jin B. The surgical treatment of carbuncles: a tale of two techniques. Iran Red Crescent Med J. 2013;15(4):367-370. doi: $10.5812 / \mathrm{ircmj} .2992$

16. Changin Huang CC, Huang Y. The origin and development of fire needle therapy. Chin Acupunct Moxibustion. 2013;33:455-458. doi:10.13703/j.0255-2930.2013.05.022

17. Huang M, Tang L, Li X, et al. Clinical observation on therapeutic effect of filiform fire needle for vitiligo: a Retrospective Study. Dermatol Ther. 2020;33(6). doi:10.1111/dth.14415

18. Pan Zhang HZ, Wang Z, Chao G, Huang P. Mechanism of fire needle therapy and its research progress in treatment of erysipelas ZHANG. Jilin J Tradit Chin Med. 2015;35:418-420. doi:10.1017/CBO978 1107415324.004

19. Min Jiang WW, Jiang K, Zeng X. Observations on the efficacy of fire needling plus medication in treating cystic acne. Shanghai $J \mathrm{Acu}$ Mox. 2015;34:1082-1084. doi:10.3969/j.issn.1005-0957.2010.11.700

20. Jun W, Rongrong S, Rongshi S. Experimental study on treatment of chronic soft tissue injuries with fire-needle therapy. Chin Acupunct Moxibustion. 2002;31-33. doi:10.3969/j.issn.1008-8849.2003.21.007

21. Aprahamian CJ, Nashad HH, DiSomma NM, et al. Treatment of subcutaneous abscesses in children with incision and loop drainage: a simplified method of care. J Pediatr Surg. 2017;52(9):1438-1441. doi:10.1016/j.jpedsurg.2016.12.018
Infection and Drug Resistance

\section{Publish your work in this journal}

Infection and Drug Resistance is an international, peer-reviewed openaccess journal that focuses on the optimal treatment of infection (bacterial, fungal and viral) and the development and institution of preventive strategies to minimize the development and spread of resistance. The journal is specifically concerned with the epidemiology of antibiotic resistance and the mechanisms of resistance development and diffusion in both hospitals and the community. The manuscript management system is completely online and includes a very quick and fair peerreview system, which is all easy to use. Visit http://www.dovepress.com/ testimonials.php to read real quotes from published authors. 